\title{
Genetic Loci That Control the Loss and Regain of Trabecular Bone During Unloading and Reambulation
}

\author{
Stefan Judex, ${ }^{1}$ Weidong Zhang, ${ }^{2}$ Leah Rae Donahue, ${ }^{2}$ and Engin Ozcivici ${ }^{3}$ \\ ${ }^{1}$ Department of Biomedical Engineering, Stony Brook University, Stony Brook, NY, USA \\ ${ }^{2}$ The Jackson Laboratory, Bar Harbor, ME, USA \\ ${ }^{3}$ Department of Mechanical Engineering, Izmir Institute of Technology, Urla, Izmir, Turkey
}

\begin{abstract}
Changes in trabecular morphology during unloading and reloading are marked by large variations between individuals, implying that there is a strong genetic influence on the magnitude of the response. Here, we subjected more than 350 second-generation (BALBxC3H) 4-month-old adult female mice to 3 weeks of hindlimb unloading followed by 3 weeks of reambulation to identify the quantitative trait loci (QTLs) that define an individual's propensity to either lose trabecular bone when weight bearing is removed or to gain trabecular bone when weight bearing is reintroduced. Longitudinal in vivo micro-computed tomography $(\mu \mathrm{CT})$ scans demonstrated that individual mice lost between $15 \%$ and $71 \%$ in trabecular bone volume fraction (BV/TV) in the distal femur during unloading (average: $-43 \%$ ). Changes in trabecular BV/TV during the 3-week reambulation period ranged from a continuation of bone loss $(-18 \%)$ to large additions $(56 \%)$ of tissue (average: $+10 \%$ ). During unloading, six QTLs accounted for $21 \%$ of the total variability in changes in BV/TV whereas one QTL accounted for $6 \%$ of the variability in changes in BV/TV during reambulation. QTLs were also identified for changes in trabecular architecture. Most of the QTLs defining morphologic changes during unloading or reambulation did not overlap with those QTLs identified at baseline, suggesting that these QTLs harbor genes that are specific for sensing changes in the levels of weight bearing. The lack of overlap in QTLs between unloading and reambulation also emphasizes that the genes modulating the trabecular response to unloading are distinct from those regulating tissue recovery during reloading. The identified QTLs contain the regulatory genes underlying the strong genetic regulation of trabecular bone's sensitivity to weight bearing and may help to identify individuals that are most susceptible to unloading-induced bone loss and/or the least capable of recovering. $\odot 2013$ American Society for Bone and Mineral Research.
\end{abstract}

KEY WORDS: RODENT; MECHANICAL LOADING; ORTHOPEDICS; BONE; EXERCISE; LINKAGE; GENE/GENETIC RESEARCH

\section{Introduction}

$\mathrm{D}$ isuse-induced osteopenia and the associated loss of bone strength can lead to severe complications both on earth as well as in space. The relative loss of tissue is site-specific and much greater in trabecular than in cortical bone, particularly predisposing sites with large trabecular content to increased fracture risk. ${ }^{(1,2)}$ Wasting of apparent trabecular bone mineral density averages approximately $2 \%$ to $3 \%$ per month for both bed rest studies and space missions. ${ }^{(3)}$ Upon reambulation, recovery rates are significantly slower than rates of bone loss, and at least some aspects of bone morphology may never return to levels seen in age-matched control subjects. ${ }^{(4,5)}$

Changes in tissue quantity during unloading and reloading are marked by large variations between individuals. During 3 months of bed rest, some subjects lose as much as $30 \%$ of their trabecular bone volume at specific sites whereas others largely maintain their bone mass. ${ }^{(6)}$ Upon return to normal ambulatory activities, not only is the rate of tissue recovery highly variable between individuals but, at least initially, some individuals may even continue to lose bone. ${ }^{(7)}$ Similar variability has been observed during spaceflight ${ }^{(2)}$ and the following reambulation phase. ${ }^{(8)}$ Considering that many environmental variables were controlled for in these studies, it was suggested that genetic variability was the main factor explaining the differential sensitivity of the skeleton to the removal and application of weight-bearing activities. This hypothesis was confirmed in inbred mouse strains that readily enable the separation of environmental from genetic variables. $^{(9)}$

In spite of clear evidence that genetic variations influence bone's response to altered mechanical environments, little is known about the identity of the genes that harbor the

Received in original form October 18, 2012; revised form January 15, 2013; accepted January 23, 2013. Accepted manuscript online February 7, 2013. Address correspondence to: Stefan Judex, PhD, Department of Biomedical Engineering, Bioengineering Building, Rm 213, Stony Brook University, Stony Brook, NY 11794-5281, USA. E-mail: stefan.judex@stonybrook.edu

Journal of Bone and Mineral Research, Vol. 28, No. 7, July 2013, pp 1537-1549

DOI: $10.1002 / \mathrm{jbmr} .1883$

(c) 2013 American Society for Bone and Mineral Research 
responsible polymorphisms. For the acquisition of peak bone mass, it is assumed that $60 \%$ to $80 \%$ of the observed variability is due to genetic variables and that this trait is polygenic, with small cumulative effects of many genes. ${ }^{(10)}$ In spite of powerful quantitative trait locus (QTL) mapping approaches in mice that have suggested several hundred loci for bone mass, morphology, and mechanics, only few responsible genes have been identified and confirmed. ${ }^{(11,12)}$ In contrast to determining the genetic basis of bone phenotypes cross-sectionally at a single time point, the identification of genetic factors that modulate changes in bone morphology by mechanical (or other) signals has to be performed longitudinally. In part because of increased complexity, much less is known about genetic factors that define the magnitude of the skeletal response to a signal. Nevertheless, when considering the large range of responses in unloading and exercises studies in both humans and mice, it is clear that the genetic influence on bone's response to changes in mechanical environment is also large and polygenic. Exploiting this genetic basis of mechanosensitivity, several genetic locations have been suggested as regulators of mechanical loading. ${ }^{(13-17)}$

To identify the genetic locations that modulate bone's response to unloading and reambulation, we performed a genetic linkage study in which two inbred strains of mice were intercrossed to form a heterogeneous F2 population. The two progenitor strains are characterized by a greatly different skeletal response to unloading; whereas the loss of weight bearing for 3 weeks reduces trabecular bone volume fraction in the femur by about $60 \%$ in female BALB/CByJ (BALB) mice, ${ }^{(9)}$ losses in male $\mathrm{C} 3 \mathrm{H} / \mathrm{HeJ}(\mathrm{C} 3 \mathrm{H})$ mice are much less. ${ }^{(18)}$ Changes in skeletal morphology were quantified by in vivo micro-computed tomography $(\mu \mathrm{CT})$ in the F2 offspring of this cross while weight bearing was removed for 3 weeks and then restored for 3 weeks. Linking phenotypic to genotypic differences across more than 350 mice enabled the determination of specific QTLs that either promoted or diminished an individual's loss of trabecular bone quantity and architecture during unloading or restored trabecular tissue during reambulation.

\section{Subjects and Methods}

\section{Experimental design}

All procedures were reviewed and approved by the Institutional Animal Care and Use Committee of Stony Brook University. Intercrossing the progenitor inbred mouse strains of female $\mathrm{BALB} / \mathrm{CByJ}$ (BALB) and male $\mathrm{C} 3 \mathrm{H} / \mathrm{HeJ}(\mathrm{C} 3 \mathrm{H})$ mice (supplied by The Jackson Laboratory [JAX], Bar Harbor, ME, USA) for two generations produced a genetically heterogeneous F2 mouse population. At 4 months of age, female F2 mice were exposed to 3 weeks of hindlimb unloading $(\mathrm{HLU})^{(9,19)}$ followed by 3 weeks of reambulation $(R A)$ involving normal cage activities. The length of the reambulation period was the same as the unloading period to capture the initial, mechanically induced response to the reintroduction of weight bearing and to minimize the influence of age-related changes in the skeletal phenotypes. ${ }^{(20)}$ In all mice, the metaphysis of the distal femur was scanned at 3-week intervals by in vivo micro-computed tomography $(\mu C T)$, coinciding with baseline, end of the unloading period, and end of the reambulation period. A total of 644 mice had a baseline scan. Because of the large total number of in vivo $\mu \mathrm{CT}$ scans required across mice and time points, only a subset of mice were subjected to hindlimb unloading $(n=464)$. A total of 352 mice completed both unloading and reambulation protocols. An additional group of F2 mice was not subjected to hindlimb unloading and served as normally ambulating age-matched controls $(n=26)$. These mice were scanned by in vivo $\mu C T$ at the same age as experimental mice. Throughout the protocol, all mice were housed singly and had ad libitum access to standard chow and water during a 12-hour light/dark cycle. Upon the last $\mu C T$ scan, mice were euthanized and the spleen was harvested and stored at $-80^{\circ} \mathrm{C}$ for DNA extraction and analysis.

\section{HLU}

Hindlimbs were elevated off the ground by a cable system connected to the tail with a 360-degree swivel, allowing the mice to move across the floor of a standard rat cage. Food pellets were dispersed on the cardboard-lined floor and water was provided in bottles attached to the cage. The barrel of a $10 \mathrm{~mL}$ syringe was secured around the tail to prevent mice from climbing onto their tails. The hindlimbs were raised over an initial 24-hour adjustment period until the mouse was unable to touch the ground with its hindlimbs.

\section{Skeletal phenotypes by in vivo $\mu \mathrm{CT}$}

Longitudinal in vivo $\mu \mathrm{CT}$ scans (VivaCT 40; Scanco Medical, Brüttisellen, Switzerland) were necessary to describe the phenotypes $^{(21)}$ because mice showed large differences in baseline morphology, precluding the quantification of altered trabecular morphology by comparing endpoint outcomes between individual mice. For each $\mu \mathrm{CT}$ scan, the mouse was anesthetized with isoflurane, ${ }^{(22)}$ and images containing both the left and right distal femur were acquired at $17.5-\mu \mathrm{m}$ voxel size (integration time $=380 \mathrm{~ms}$; number of projections $=1000$; energy $=55 \mathrm{kV}$, intensity $=109 \mu \mathrm{A}$ ).

Each scan delivered a CT dose index (CTDI) of about $340 \mathrm{mGy}$ as estimated by the manufacturer with a $35-\mathrm{mm}$ phorbol myristate acetate (PMA) cylinder that mimicked soft tissue of the mouse. Radiation effects on bone are not well established. A large single dose of $2000 \mathrm{mGy}$ may induce bone loss in mice, ${ }^{(23)}$ but this dose did not exacerbate disuse-induced bone loss. ${ }^{(24)}$ The consequences of repetitive exposures to much smaller radiation levels associated with $\mu \mathrm{CT}$ scans are also not clear. Three consecutive scans at 2-week intervals (430 mGy each) had no effect on trabecular and cortical bone architecture, peripheral blood cell counts, and colony-forming capacity of hematopoietic progenitor cells in rapidly growing or adult C57BL/6 mice. ${ }^{(25)}$ Similarly, eight weekly in vivo scans of 940 mGy each did not change bone morphology in rats. ${ }^{(26)}$ Adverse effects have been observed, however, in rapidly growing mice in which four weekly scans at 850 $\mathrm{mGy}$ deteriorated trabecular bone volume in the tibia. ${ }^{(27)}$

Although these data suggest that our scanning protocol was unlikely to affect our data, we directly tested whether radiation may have influenced bone morphology during the unloading phase and during normal ambulation. In 30 mice, baseline scans were performed only on the right femoral metaphysis 
while the left legs were shielded from exposure. After 3 weeks of unloading $(n=20)$ or normal ambulation $(n=10)$, the metaphyses of both legs were scanned and compared to each other. Another group of mice was unloaded for 3 weeks and, in addition to the final scan at euthanasia, was scanned either three times at weekly intervals $(n=25)$ or only at baseline $(n=15)$.

The scan resolution was chosen as a compromise between the requirements to keep the levels of ionizing radiation as low as possible, and the ability to analyze the trabecular structure with high accuracy as the numerical values of trabecular $\mu C T$ variables can be dependent on scanning voxel size. ${ }^{(21)}$ The voxel size used in our study was not small enough to consistently contain three to four voxels across all trabeculae, which has been recommended to minimize errors, ${ }^{(21)}$ but trabeculae contained at least two voxels across even after unloading, a resolution that is high enough to enable the detection of differences between a normal and osteoporotic state. ${ }^{(28)}$ It is entirely possible that the selected voxel size introduced a bias in trabecular structures with thick trabeculae versus thin trabeculae. Ostensibly, this bias may reduce the logarithm of the odds (LOD) score for any given QTL region but will unlikely produce a significant shift of the QTL region because the bias should be relatively uniform across those mice with a given phenotype (and most trabecular variables are at least to some degree dependent on each other).

Trabecular bone was separated from the surrounding cortex using a semiautomatic algorithm, ${ }^{(29)}$ followed by a Gaussian noise reduction $(\sigma=0.3$, support $=1)$ and global thresholding at $29.5 \%$ of the maximum grayscale value. Trabecular morphology of the segmented tomography was evaluated for trabecular bone volume fraction (BV/TV), connectivity density (Conn.D), thickness (Tb.Th), number (Tb.N), bone surface per volume (BS/BV), and tissue mineral density (TMD). All outcome variables were averaged across the left and right leg of each mouse. Baseline trabecular phenotypes included all morphological variables at 4 months of age, prior to starting the experimental phase. Unloading and reambulation phenotypes were computed as relative longitudinal differences of all outcome variables between the end of unloading/reambulation and the previous scan time point.

\section{Genotyping}

Tail tips from F2 female mice were submitted to the single nucleotide polymorphism (SNP) genotyping service at JAX. DNA was prepared using established phenol chloroform methods and submitted to KBiosciences (UK) for SNP genotyping. With direction from JAX, KBiosciences has developed over 2350 working SNP assays using the Amplifluor technique. SNPs were spaced at approximately 1-megabase $(\mathrm{Mb})$ intervals across the genome. From this set, 89 SNPs known to be polymorphic between the $B A L B / C B y J$ and $\mathrm{C} 3 \mathrm{H} / \mathrm{HeJ}$ inbred strains were selected for genotyping the set of F2 mice.

\section{Statistical phenotype analysis}

Only those mice that completed both the unloading and reambulation phase were included in the presentation of the skeletal phenotypes $(n=352)$. To avoid outliers, minimal and maximal values of any given phenotype were reported as the 5 th and 95th percentile of the population, with the range representing the difference between these two percentiles. Paired $t$ tests compared individual phenotypes between two different time points, whereas unpaired $t$ tests compared data between experimental and age-matched control mice. Across the baseline and the two experimental phases, individual skeletal phenotypes were associated with each other via linear regressions. To identify radiation effects, bone morphology was compared between left and right legs via paired $t$ tests, whereas unpaired $t$ tests were used to compare changes in bone morphology between mice that were scanned either weekly or only at baseline. For all statistical analyses, $p<0.05$ was considered statistically significant.

\section{QTL mapping}

QTL analysis was performed for all baseline, unloading, and reambulation phenotypes using the statistical software R/QTL (version 1.16-6). ${ }^{(30)}$ The distributions of BV/TV, BS/BV, and Conn. $D$ were square-root transformed to adjust for skewed distributions. The other outcome variables (phenotypes) did not require transformation because their distributions did not show substantial normality violations.

For genomewide one-dimensional scans, pseudomarkers were generated at 2-cM (2 centimorgan) spacing for each chromosome and scans were performed using 256 imputations. $^{(31)}$ The thresholds for QTL detection were computed from 1000 permutations. ${ }^{(32)}$ Four thresholds, $1 \%, 5 \%, 10 \%$, and $63 \%$, were calculated from the permutation results. QTLs with LOD scores above the $1 \%$ threshold were strong QTLs, whereas those above 63\% were suggestive QTLs. ${ }^{(33)}$

For genomewide two-dimensional scans, pairwise scans were performed at 2-cM spacing. On each chromosome, all possible pairs of QTL locations were tested for association with the phenotypes. The likelihood from the full model (pseudomarker pair and the interaction between them) was compared to the null model (no genetic effect) and LOD scores were calculated. In addition, LOD scores were calculated that resulted from the comparison between the likelihood from the full model and the additive model (with only the main effects of pseudomarkers and but no interaction).

QTL and possible QTL ${ }^{*}$ QTL interactions identified from a single and pairwise QTL scan were fit into multiple regression models, facilitating the estimation of the variations of the phenotype in the models. Values of $p$ for terms in the multiple regression model were determined. Terms were dropped sequentially until all of the terms in the model were significant at the $1 \%$ level for main QTL effects and at $0.1 \%$ for interaction effects. For any QTL that was characterized as strong, effect plots were generated for the autosomal region by stratifying the mice based on homozygous (BALB or $\mathrm{C} 3 \mathrm{H}$ ) or heterozygous alleles (BALB and $\mathrm{C} 3 \mathrm{H})$. Gene lists were generated with biomaRt 2.8.1. ${ }^{(34)}$ The NCBI Mus musculus gene database (NCBIM37) and Mus musculus variation database (dbSNP128) were used to retrieve genes and SNPs within the $95 \%$ confidence interval of each QTL. Genes that do not have polymorphisms between $\mathrm{C} 3 \mathrm{H}$ and BALB were excluded. 
Table 1. Trabecular Morphology of the Distal Femur at Baseline

\begin{tabular}{|c|c|c|c|c|c|c|}
\hline & \multicolumn{3}{|c|}{ Experimental } & \multicolumn{3}{|c|}{ Age-Matched Control } \\
\hline & Mean & Minimum & Maximum & Mean & Minimum & Maximum \\
\hline $\mathrm{BV} / \mathrm{TV}(-)$ & 0.21 & 0.05 & 0.43 & 0.22 & 0.09 & 0.43 \\
\hline BS/BV $(1 / \mathrm{mm})$ & 35 & 22 & 52 & 34 & 21 & 42 \\
\hline Conn.D $\left(1 / \mathrm{mm}^{3}\right)$ & 87 & 33 & 192 & 93 & 34 & 150 \\
\hline Tb.N (1/mm) & 4.4 & 1.5 & 6.7 & 4.6 & 2.7 & 6.4 \\
\hline Tb.Th (mm) & 0.07 & 0.04 & 0.09 & 0.07 & 0.06 & 0.09 \\
\hline $\mathrm{TMD}\left(\mathrm{mgHA} / \mathrm{cm}^{3}\right)$ & 846 & 776 & 908 & 841 & 802 & 924 \\
\hline
\end{tabular}

Values are the mean, minimal, and maximal values of any given variable across the 352 experimental and 26 control female mice that completed the entire protocol.

$\mathrm{BV} / \mathrm{TV}=$ bone volume fraction; $\mathrm{BS} / \mathrm{BV}=$ bone surface per volume; Conn. $\mathrm{D}=$ connectivity density; $\mathrm{Tb} . \mathrm{N}=$ trabecular number; Tb.Th=trabecular thickness; TMD $=$ tissue mineral density.

\section{Results}

\section{Trabecular bone morphology at baseline}

At baseline, bone volume fraction in the metaphysis was on average $21 \%$ (Table 1). As expected in this genetically heterogeneous population, individual mice displayed large differences in most measures of bone morphology at 4 months of age. Coefficient of variations (CV) were high for BV/TV (38\%) and Conn.D (38\%), moderate for BS/BV (16\%), Tb.N (19\%), and Tb. Th (12\%), and relatively small for TMD (3\%) (Table 1, Fig. 1). F2 mice that served as age-matched controls had similar phenotypic variations as experimental mice at baseline: BV/TV (36\%), Conn.D (29\%), Tb.N (18\%), Tb.Th (14\%), BS/BV (16\%), and TMD (4\%) (Table 1).

Changes in bone morphology during unloading and reambulation

Similar to individual differences in baseline bone morphology at 4 months of age, F2 mice showed distinct responses to both unloading and reambulation. Unloading of the hindlimbs diminished ( $p<0.0001$ each), on average, BV/TV by $43 \%$ (range, $15 \%$ to $71 \%$ ), Conn.D by $38 \%$ (range, $2 \%$ to $79 \%$ ), Tb.N by $30 \%$ (range, $7 \%$ to $30 \%$ ), Tb.Th by $18 \%$ (range, $4 \%$ to $29 \%$ ), and TMD by $3 \%$ (range, $-2 \%$ to $7 \%$ ). The ratio of $\mathrm{BS} / \mathrm{BV}$ increased by $28 \%$ (range, $5 \%$ to $51 \%$ ) (Figs. 1, 2). Morphological changes in normally ambulating, age-matched controls were relatively small during this 3-week period and reached statistical significance only for BV/TV (-9\%), Conn.D (-18\%), and Tb.N (-9\%) (Fig. 2). For each morphological variable, changes in unloaded mice were much greater than in controls ( $p<0.0001$ each). No radiation effects were evident in unloaded (Fig. 3) or control (data not shown) mice because changes in BV/TV (and architectural variables) were virtually identical in limbs with and without radiation as well as between mice exposed to either weekly scans or a baseline scan only (significance for all comparisons $p>0.6$ ).

The response of trabecular bone to reambulation was also dependent on genetic makeup (Fig. 1). Averaged across all mice, some aspects of trabecular morphology started to recover, whereas others continued to deteriorate during this brief 3-week reambulation phase. On average ( $p<0.0001$ each), BV/TV increased by $10 \%$ (range, $-18 \%$ to $56 \%$ ), Tb.Th by $16 \%$ (range,
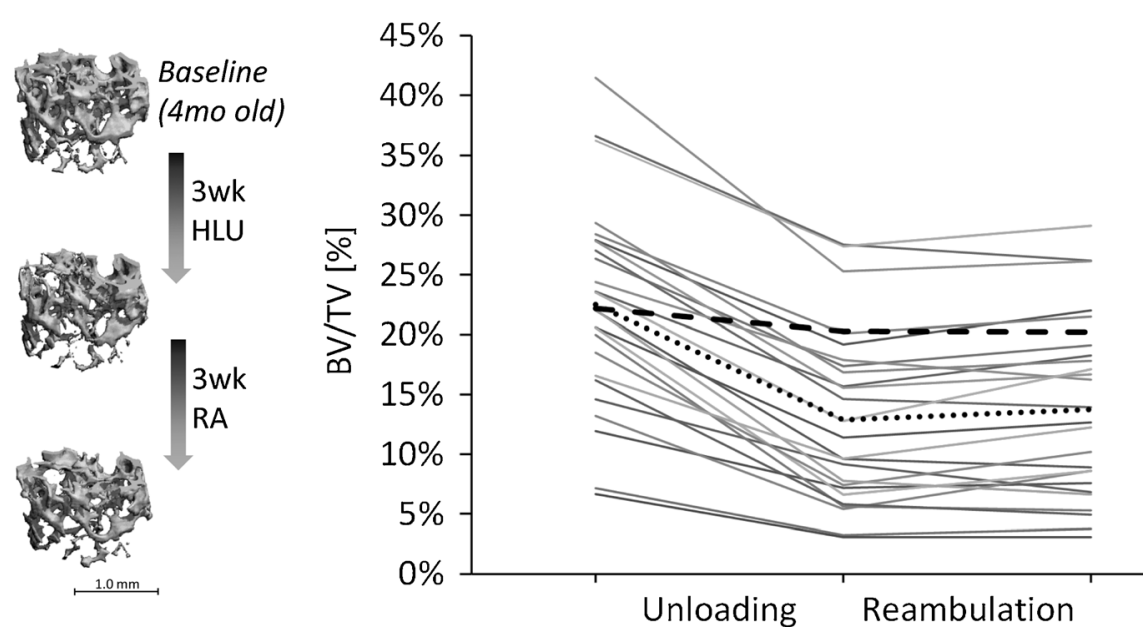

Fig. 1. Trabecular bone volume fraction (BV/TV) of 25 randomly selected mice at baseline, after 3 weeks of unloading and after 3 weeks of reambulation. The dotted line shows the mean of the 25 experimental mice whereas the dashed line represents the mean of 26 normally ambulating control mice over the same time period. 

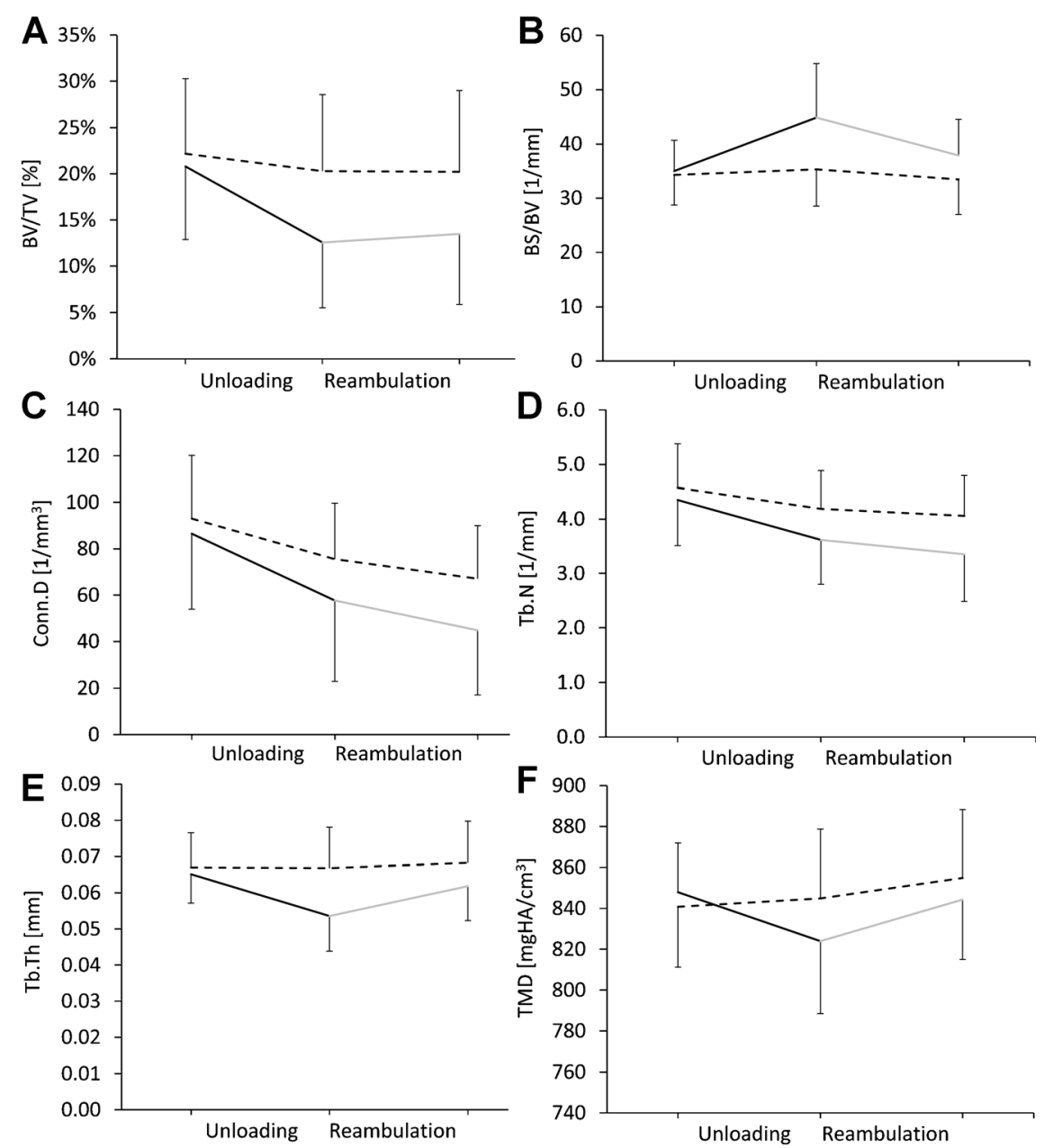

Fig. 2. Mean and SD of trabecular variables describing the distal femoral diaphysis of mice at baseline and subjected to 3 weeks of unloading followed by 3 weeks of reambulation $(n=352)$. Changes in normally ambulating control mice are shown by a dashed line $(n=26) ;(A)$ bone volume fraction, $(B)$ bone surface over bone volume, $(C)$ connectivity density, $(D)$ trabecular number, $(E)$ trabecular thickness, and $(F)$ tissue mineral density.

$2 \%$ to $33 \%$ ), and TMD by $3 \%$ (range, $-1 \%$ to $6 \%$ ), whereas Conn.D decreased by $18 \%$ (range, $-55 \%$ to $28 \%$ ), Tb.N by $8 \%$ (range, $-21 \%$ to $3 \%$ ), and BS/BV by $15 \%$ ( $-3 \%$ to $27 \%$ ) (Fig. 2). In the trabecular metaphysis of normally ambulating age-matched controls, Conn.D (-12\%), Tb.N (-3\%), Tb.Th (2\%), TMD (1\%), and BS/BV (5\%) were all altered during this 3-week period (Fig. 2). With the exception of Conn.D, the alteration of morphologic indexes in unloaded mice was significantly different from control mice.

\section{Body mass and its relation to bone morphology}

Experimental mice lost about $15 \%$ of their baseline body mass during unloading and gained $8 \%$ body mass (relative to their
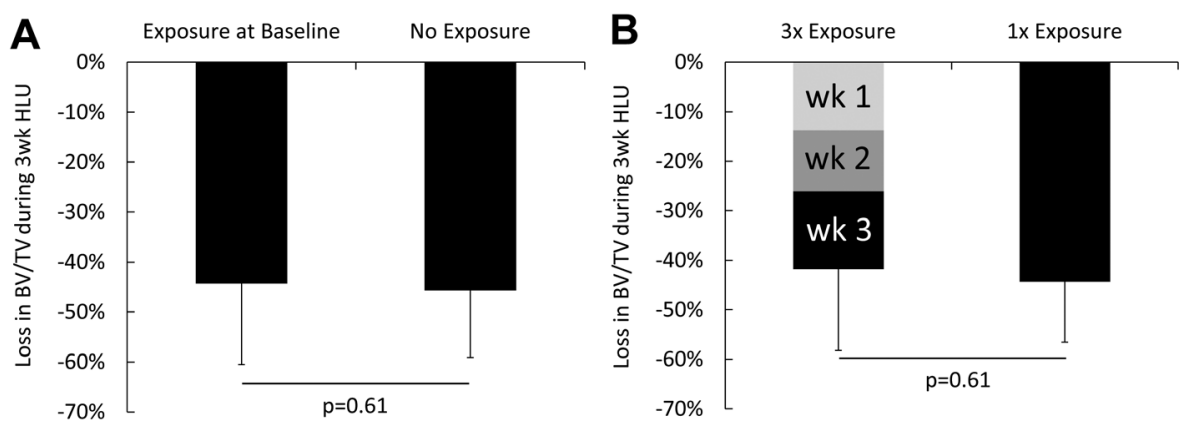

Fig. 3. To test for radiation effects associated with $\mu \mathrm{CT}$ scanning, the loss of bone volume fraction in the distal femoral metaphysis during 3 weeks of hindlimb unloading was monitored in mice that were subjected to different levels of radiation. $(A)$ Comparison between right and left legs that, prior to endpoint scanning, were exposed (right leg) or shielded (left leg) from $\mu C T$-induced radiation at baseline. (B) Comparison of HLU-induced reductions in BV/TV between groups of mice in which the distal femoral metaphysis was either exposed to three weekly scans or only one scan at baseline (prior to endpoint scan). Subdivisions within the $3 \times$ Exposure group represent the relative loss of trabecular bone during the first, second, and third week of unloading. 
unloaded state) during reambulation ( $p<0.0001$ each). In normal control mice, body mass did not change significantly over the 6-week period $(+2 \%)$. We performed correlations between body mass and bone morphological variables at baseline as well as between their changes during unloading and reambulation to test the dependency of trabecular bone morphology on body mass. $R^{2}$ values for correlations at baseline were very small, ranging from 0.01 for Conn.D to 0.05 for BS/BV. Correlations for changes in body mass and changes in bone morphology during the two experimental phases were even smaller (all $R^{2}<0.05$ ).

Morphologic relations between baseline, unloading, and reambulation

Linear regressions were used to identify associations between baseline morphology and altered morphology induced by HLU and RA. The link between femoral trabecular morphology present prior to initiating $\mathrm{HLU}$ and the change in morphologic variables during $\mathrm{HLU}$ was weak to moderate. All associations were negative in nature. For instance, smaller BV/TV and Conn.D at baseline $(\mathrm{BL})$ correlated with a greater relative loss in BV/TV and Conn.D during $\mathrm{HLU}\left(R^{2}=0.27\right.$ and $\left.R^{2}=0.21\right)$, whereas the correlative strength was less for the other variables $\left(R^{2}=0.05-\right.$ 0.11 ; Table 2). The morphologic variables quantified at the transition from HLU to RA that were best capable of predicting the change induced by RA were distinct from those that had the highest $R^{2}$ values for the correlations between baseline and HLUinduced changes; $R^{2}$ values for Tb.Th $\left(R^{2}=0.29\right), \operatorname{TMD}\left(R^{2}=0.34\right)$, and $\mathrm{BS} / \mathrm{BV}\left(R^{2}=0.36\right)$ were greater than for the other variables $\left(R^{2}=0.04-0.05\right.$; Table 2). Similar to correlations obtained for HLU, the correlations for RA were also negative (with the exception of Tb.N). Thus, smaller morphologic values prior to initiating HLU and RA led to greater relative changes during HLU and RA. In contrast, for any given morphologic variable (with the exception of Tb.N), a greater change during HLU was associated with a

Table 2. Coefficients of Determination $\left(R^{2}\right)$ for the Association Between Any Given Morphologic Variable at Baseline (BL), Immediately After Completing the Unloading Phase (HLU), and the Change During HLU $(\Delta H L U)$ and RA $(\Delta R A)$

\begin{tabular}{lccc}
\hline & BL- $\Delta$ HLU & HLU- $\Delta$ RA & $\Delta$ HLU- $\Delta$ RA \\
\hline BV/TV & $0.27(-)$ & $0.04(-)$ & 0.03 \\
Conn.D & $0.21(-)$ & $0.05(-)$ & 0.07 \\
Tb.N & $0.05(-)$ & 0.05 & $0.13(-)$ \\
Tb.Th & $0.11(-)$ & $0.29(-)$ & 0.33 \\
TMD & $0.05(-)$ & $0.34(-)$ & 0.39 \\
BS/BV & $0.08(-)$ & $0.36(-)$ & 0.30 \\
\hline
\end{tabular}

$p<0.001$ for all regressions.

$(-)=$ negative association; $\mathrm{BL}=$ baseline; $\mathrm{HLU}=$ unloading phase; $\Delta \mathrm{HLU}=$ change during unloading phase; $\mathrm{RA}=$ reambulation; $\triangle \mathrm{RA}=$ change during reambulation phase; $\mathrm{BV} / \mathrm{TV}=$ bone volume fraction; Conn. $\mathrm{D}=$ connectivity density; $\mathrm{Tb} . \mathrm{N}=$ trabecular number; $\mathrm{Tb} . \mathrm{Th}=$ trabecular thickness; $\mathrm{TMD}=$ tissue mineral density; $\mathrm{BS} / \mathrm{BV}=$ bone surface per volume. greater change during $\mathrm{RA} ; R^{2}$ values were greater for Tb.Th, TMD, and $\mathrm{BS} / \mathrm{BV}\left(R^{2}=0.30-0.39\right)$ than for the other three variables $\left(R^{2}=0.03-0.07\right)$

\section{QTLs modulating trabecular morphology at baseline}

Genomewide scans identified significant QTLs for BV/TV, Conn. D, Tb.N, Tb.Th, TMD, and BS/BV at baseline (Fig. 4). The location of the genetic loci was similar within the group of BV/TV, Conn. $\mathrm{D}$, and Tb.N as well as within the group of Tb.Th, BS/BV, and TMD. The percent of trait variability that was accounted for by all significant QTLs at baseline was $15 \%$ for BV/TV, $16 \%$ for Conn.D, $19 \%$ for Tb.N, $9 \%$ for Tb.Th, 27\% for TMD, and $6 \%$ for $\mathrm{BS} / \mathrm{BV}$.

QTLs modulating changes in trabecular morphology induced by unloading/reambulation

Changes in trabecular morphology during unloading and reambulation were also linked to individual variations in the genome of F2 mice (Fig. 4). During unloading, more than $20 \%$ of the variability in the reduction in BV/TV was explained by the genomic variability in six different chromosomal locations. Of these six QTLs, five promoted and one reduced the magnitude of bone loss in BALB when compared to $\mathrm{C} 3 \mathrm{H}$ (Fig. 5). The QTL on chromosome 8 ( $\mathrm{Chr} 8$ ) was shared between baseline BV/TV and the change in BV/TV during unloading, whereas the others were independent (Fig. 4). QTLs of trabecular architectural variables explained between $3 \%$ and $20 \%$ of the variability in the HLUinduced changes of any given variable (Table 3). Similar to BV/TV, there was little to moderate overlap between QTLs linked to baseline architecture and QTLs linked to architectural changes; two QTLs were shared for Conn.D, one for Tb.N, two for Tb.Th, one for BS/BV, and one for TMD. There was moderate overlap between QTLs for any given architectural variable with other variables during unloading, one QTL on Chr 1 was shared between Conn.D and TMD, on Chr 2 between BV/TV, Tb.Th, and $\mathrm{BS} / \mathrm{BV}$, on Chr 3 between BV/TV and BS/BV, on Chr 5 and 6 between Tb.Th, TMD, and BS/BV, on Chr 7 between BV/TV and Conn.D, and on Chr 8 between BV/TV, Conn.D, Tb.Th, Tb.N, and TMD.

Fewer significant QTLs linking genetic differences to the phenotypic response were identified for reambulation than for unloading. No significant QTLs were found for Conn.D. Compared to unloading, QTLs associated with reambulation accounted also for a smaller percentage of the variability in the phenotype compared to QTLs associated with unloading. The QTL for BV/TV on Chr 13 accounted for $6 \%$ of the variability in the changes in BV/TV during reambulation (Table 3, Fig. 5), whereas QTLs pertaining to architectural variables accounted for $9 \%$ to $17 \%$ of the variability in any given variable across all mice (Table 3). Genomic-phenotypic relations for reambulation were the most similar for BV/TV, BS/BV, Tb.Th, and TMD. QTL regions that regulated bone's response to reambulation were mostly distinct from those that regulated bone morphology at baseline or changes in it during unloading. One QTL on Chr 9 was shared between reambulation and baseline for Tb.Th, BS/BV, and TMD, whereas for TMD, a QTL on Chr 8, was shared between HLU and RA (Table 4, Fig. 4). 

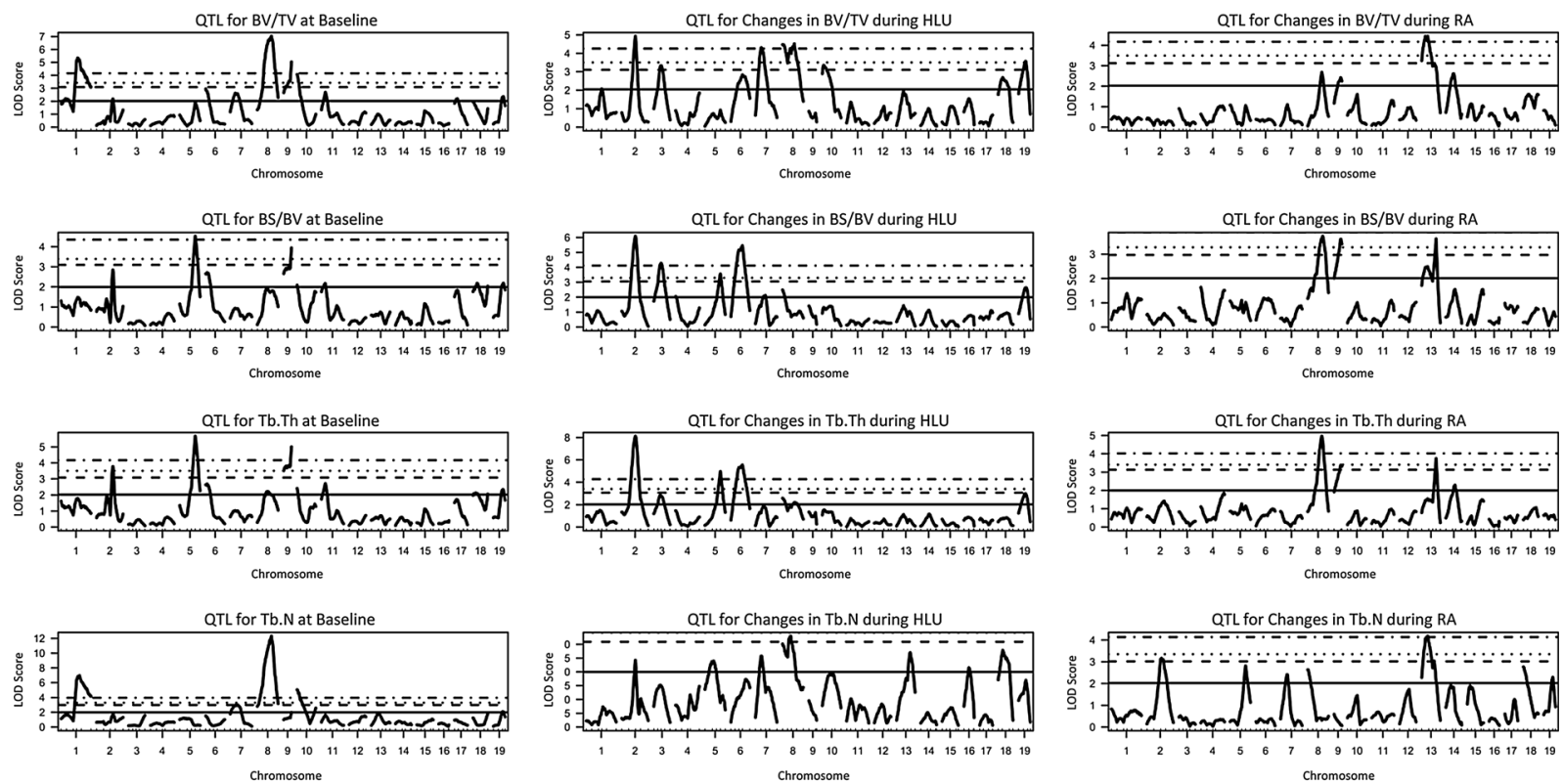
Chromosome Chromosome
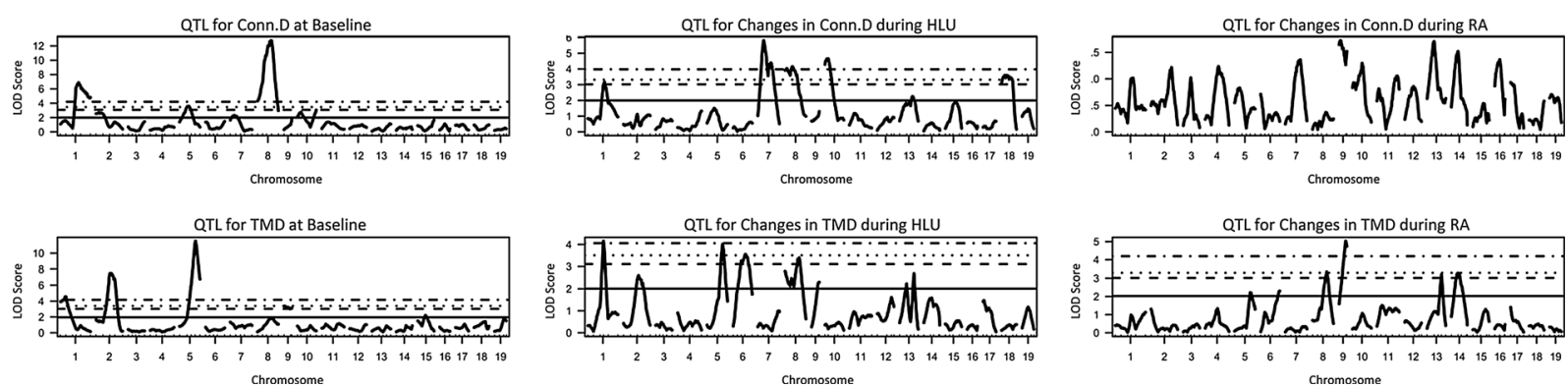

Fig. 4. Genomewide scans identified QTLs for trabecular morphology at $(A)$ baseline $(n=644)$ and for the changes in morphological variables during $(B)$ unloading $(n=464)$ and $(C)$ reambulation $(n=352)$. The solid, dash, dot, and dash-dot lines denote significance thresholds of $63 \%, 10 \%, 5 \%$, and $1 \%$, respectively.

\section{Discussion}

We generated several hundred genetically heterogeneous mice with a large range of sensitivity to altered mechanical demand. Upon removal of weight bearing, some mice were largely protected from the subsequent catabolic pressure whereas others lost most of their trabecular bone in the distal femur, with devastating consequences for its architecture. Similarly, the reintroduction of ambulation did not stop bone loss in some mice whereas others regained their baseline bone volume prior to unloading. This differential mechanosensitivity facilitated the identification of QTLs modulating the changes in bone morphologic variables. Most of the QTLs that regulated changes during unloading or reambulation did not overlap with those QTLs identified at baseline, suggesting that these QTLs harbor genes that are specific to defining bone's response to altered mechanical demand. The limited overlap in QTLs between unloading and reambulation, together with low phenotypic correlations between the two experimental phases, also emphasizes that the genes modulating the trabecular response to unloading are distinct from those regulating tissue recovery during reloading. Ultimately, this work may lead to defining regulatory genes of bone's sensitivity to altered mechanical signals and serve toward the identification of those individuals that are most susceptible to unloading induced bone loss and/or the least capable of recovering.

The inbred progenitor mouse strains were selected based on the differential susceptibility of their skeletons to unloading. ${ }^{(9,35)}$ Although segregation of the alleles from the two genetically distinct inbred strains resulted in $\mathrm{F} 2$ mice with random assortment of susceptible and protective alleles, this variability does not resemble the much broader variability across the entire mouse genome. Thus, QTLs identified here only reflect polymorphisms in genes that differentially modulate bone's susceptibility to unloading and reloading in $\mathrm{BALB}$ and $\mathrm{C} 3 \mathrm{H}$, and the selection of different progenitor strains may unravel additional QTLs. Nevertheless, the advantage of using BALB as the mechanically responsive progenitor strain was that, unlike $\mathrm{C} 57 \mathrm{BL} / 6 \mathrm{~J}$ mice that also display a high sensitivity to the removal/application of mechanical signals, the baseline morphology of BALB is much more similar to $\mathrm{C} 3 \mathrm{H}$ mice, reducing the likelihood of confounding factors associated with baseline morphology. Another benefit of using these two inbred strains was that the F2 mice, on average, largely maintained their trabecular bone volume during the 6week period and therefore limited the potential interaction with aging effects that cannot be discounted in B6 mice. ${ }^{(20)}$

Previous studies performed primarily in mice, identified more than 100 QTLs associated with bone phenotypes including bone 
A
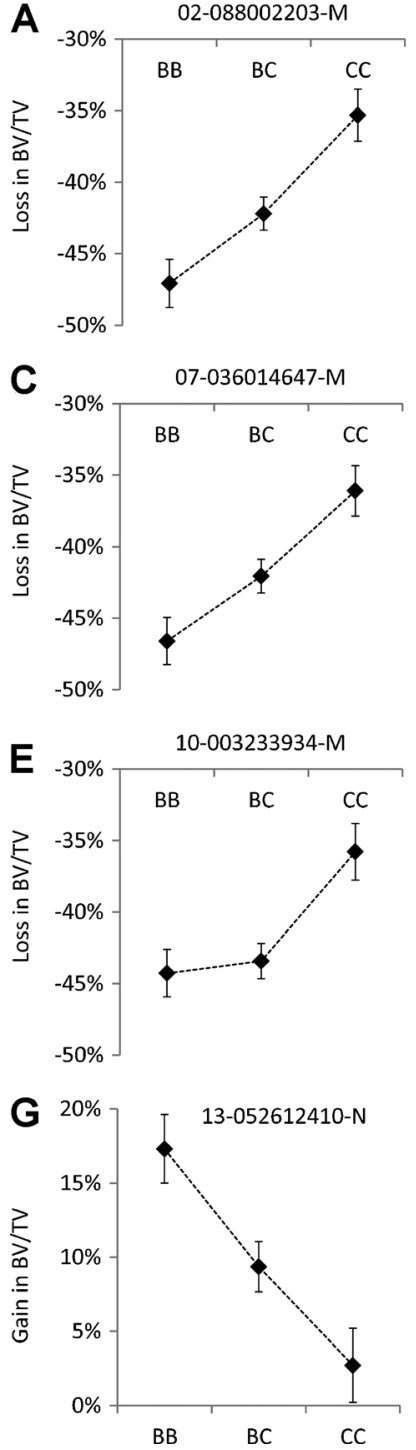
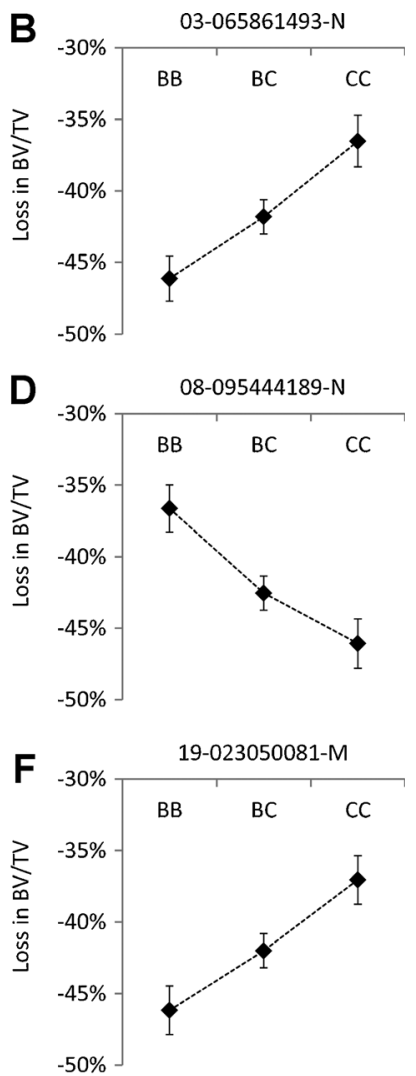

Fig. 5. Effect plots for significant QTLs modulating changes in bone volume fraction (BV/TV) during $(A-F)$ unloading and $(G)$ reambulation. morphology or bone mechanical properties. Not surprisingly, some of the genomic regions identified as QTLs in this study overlapped with previously reported QTLs (Table 4). In particular, bone mineral density 39 (BMD39) $^{(17)}$ and bone response to mechanical loading 2 (BRML2), ${ }^{(16,36)}$ both of which reside on $\mathrm{Chr}$ 8 , have been previously suggested as important in regulating bone's responsiveness to exogenous mechanical signals. Mice that carried alleles from the $\mathrm{C} 3 \mathrm{H}$ progeny onto a $\mathrm{B} 6$ background at BMD39 showed reduced responsiveness to in vivo ulna loading based on cortical BMD phenotyping. ${ }^{(17)}$ The BRML2 locus was not only identified as a modulator of cortical BMD to exogenously applied mechanical loads but also for regulating alkaline phosphatase and bone sialoprotein activity of the F2 progeny of $\mathrm{B} 6$ and $\mathrm{C} 3 \mathrm{H}$ strains. ${ }^{(16,36)}$ Our study showed that a gene at this locus may also modulate trabecular BV/TV, Conn.D, Tb.N, and TMD to unloading, and Tb.Th, TMD, and BS/BV to reambulation. Other QTLs observed within these 95\% confidence intervals on Chr 8 have been related to geometric and mechanical properties of the mouse femur, suggesting that this gene may have multiple functions.

The QTL that was associated with the regulation of the largest number of phenotypes during reambulation (BV/TV, Tb.N, Tb.Th, TMD, and BS/BV) resided on Chr 13. Within the 95\% confidence interval of this locus, no QTLs for mechanical loading have been proposed previously, but QTLs for other bone-related traits have been suggested. For instance, proteasome subunit beta type-2-B (PBD2) was identified in SAMP mice by microphotodensitometry as a locus that controls peak bone mass. ${ }^{(37,38)}$ Further, BMD13 is an additive modulator of pQCT-based BMD in B6XC3H crosses. ${ }^{(39)}$ Together, these data suggest that either the regulatory gene for the reambulation QTL on this chromosome is distinct from the gene underlying the previously determined QTLs for high bone mass, the previous bone density QTLs are based on mechanical effects, or the pathways for bone development and bone's plasticity to the application of mechanical signals share a common element.

Table 3. Summary of the Number of QTLs Identified for Each Morphologic Variable During Unloading and Reambulation

\begin{tabular}{|c|c|c|c|c|}
\hline Condition & Index & LOD & Trait variation (\%) & QTL $(n)$ \\
\hline \multirow[t]{6}{*}{ Unloading } & $\mathrm{BV} / \mathrm{TV}$ & 24.6 & 22 & 6 \\
\hline & Conn.D & 22.1 & 20 & 5 \\
\hline & Tb.N & 3.3 & 3 & 1 \\
\hline & Tb.Th & 17.2 & 16 & 3 \\
\hline & $\mathrm{BS} / \mathrm{BV}$ & 19.2 & 17 & 4 \\
\hline & TMD & 15.0 & 19 & 4 \\
\hline \multirow[t]{6}{*}{ Reambulation } & $\mathrm{BV} / \mathrm{TV}$ & 4.4 & 6 & 1 \\
\hline & Conn.D & - & - & - \\
\hline & Tb.N & 7.3 & 9 & 2 \\
\hline & Tb.Th & 12.0 & 15 & 3 \\
\hline & $\mathrm{BS} / \mathrm{BV}$ & 10.6 & 13 & 3 \\
\hline & TMD & 13.8 & 17 & 4 \\
\hline
\end{tabular}

The cumulative LOD score and the percent of trait variation that is accounted for by the sum of significant QTLs is provided for any given outcome variable. $\mathrm{QTL}=$ quantitative trait locus; $\mathrm{LOD}=$ logarithm of the odds; $\mathrm{BV} / \mathrm{TV}=$ bone volume fraction; Conn.D. = connectivity density; Tb.N $=$ trabecular number; $\mathrm{Tb} . \mathrm{Th}=$ trabecular thickness; $\mathrm{BS} / \mathrm{BV}=$ bone surface per volume; $\mathrm{TMD}=$ tissue mineral density. 


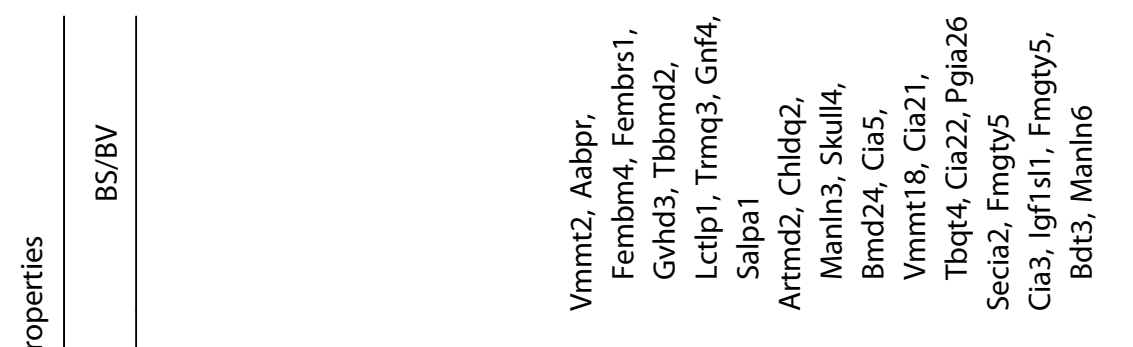

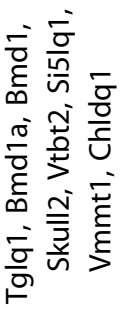
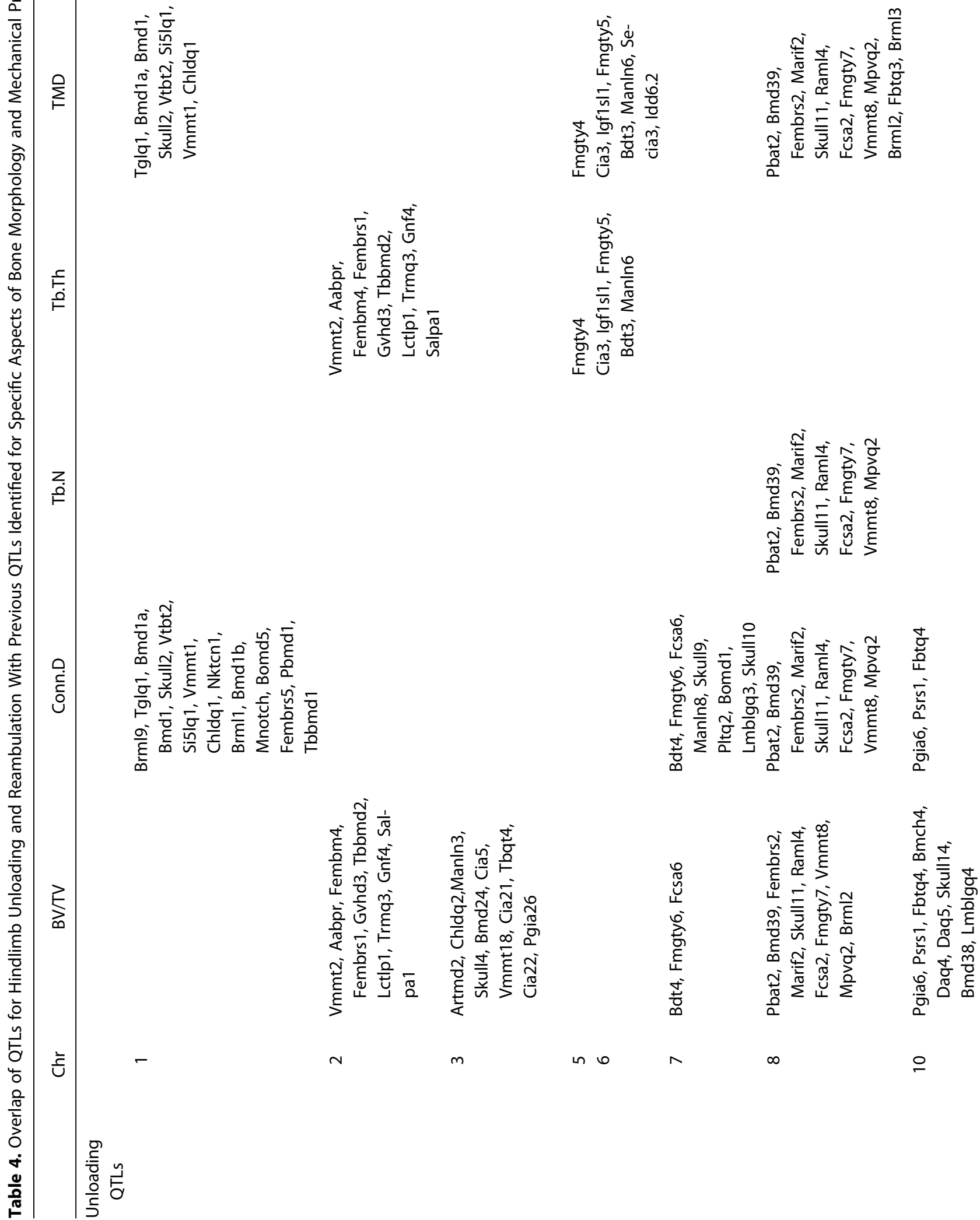

$N$

$\infty$

으 


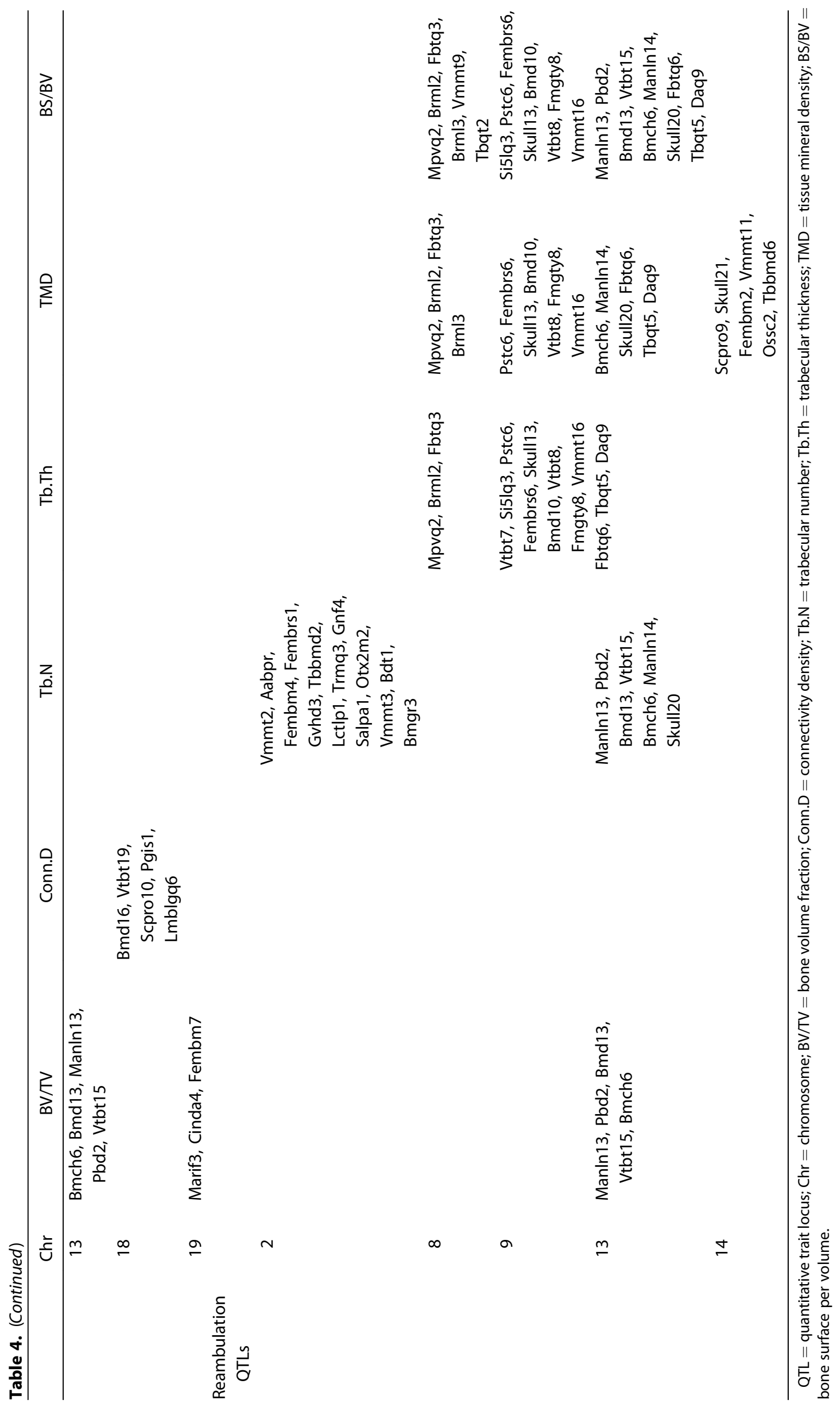


Table 5. Overlap of Genes Previously Proposed to be Involved in Bone's Response to Unloading and Loading With Genes Within the $95 \%$ Confidence Intervals of QTLs for Changes in BV/TV

\begin{tabular}{lc}
\hline Condition & Common genes \\
\hline Unloading & S100a6, Actc1, Cdh11, Ptx3, Clec11a, Akap12, Scd2, Gas2, Dbp, Csrp3, Asb5, Myod1, Fxyd1, Aldh1a1, Pdlim3, Cdc16, \\
& Retn, Ctsk, Col4a2, Cpe, Tm4sf1, Esr1, Lrp4, Comp, Kazald1, F2, Calr3, Slc39a13, Lrrc4c, Sbsn, Olfml3, Ndufc1, Scd1, \\
& Nr2f2, Cbara1, Serping1, Bcat2, Gfm1, H47, S100a16, Atp6v1b2, Elmod2, Olfr1271, Gda, Cd2, S100a9, Ckap5, \\
& S100a11, Cyp26a1, Anp32e, Brf2, Hmox1, Olfr1506, Slk, Ccar1, 2610021A01Rik, Rnaseh2a, Fcer2a, Cd22, \\
& Shcbp1, Fbxo5 \\
Loading & 4930528D03Rik, Cap2, Fbp2, Akr1e1, Agtpbp1, Actn2, Ctsl, Ctsm, Serpinb6a, Gmds, Ptch1, Sfrp4 \\
\hline
\end{tabular}

Genes that do not contain SNPs between C3H and BALB strains were excluded from this search.

$\mathrm{QTL}=$ quantitative trait locus; $\mathrm{BV} / \mathrm{TV}=$ bone volume fraction; $\mathrm{SNP}=$ single nucleotide polymorphism.

The determination of QTLs represents a critical step toward defining the genetic influence on trabecular phenotypes during unloading and reambulation, but further studies are required to identify the underlying individual genes from the typically 100 to 500 genes residing in each QTL interval. ${ }^{(40)}$ Several approaches are available-from computational to experimental or a combination of the two. Because these additional studies would require congenic strains, additional crosses, bioinformatics, and/or gene expression analyses, they are outside the scope of the current study. For instance, haplotype analyses can be very effective in narrowing a QTL region, ${ }^{(41)}$ but require the generation of additional multiple crosses (F2s or N2s) or inbred strains subjected to unloading. Similarly, association mapping using a diversity outbred mouse (http://churchill.jax.org/research/cc.shtml), a new mapping resource, would necessitate the phenotyping and highdensity SNP array genotyping of approximately 300 unloaded mice. Further, any gene variant suggested by a given approach will ultimately require in vivo validation. ${ }^{(42)}$

Even though considerable work will be required to determine the causative genes within the QTLs identified here, genes within the $95 \%$ confidence intervals of the QTLs can be compared to genes previously identified to play a role in the pathways by which bone responds to (un)loading. To this end, we considered 1100 unloading and 1428 loading genes that have recently been found significantly upregulated or downregulated, with unloading in a rotating wall vessel bioreactor ${ }^{(43)}$ and after sciatic neurectomy, ${ }^{(44)}$ and with (re)loading using in vitro fluid shear ${ }^{(45)}$ or an in vivo loading model with ${ }^{(44)}$ or without sciatic neurectomy. ${ }^{(44,46)}$ Contrasting these genes with those that harbor polymorphisms between the BALB and $\mathrm{C} 3 \mathrm{H}$ strains and are contained in QTLs for changes in BV/TV during unloading and reambulation yielded 61 common genes for unloading and 12 genes for (re)loading (Table 5). Unloading candidate genes encoded for cytoskeletal elements (eg, Actc1, Akap12), growth modulating genes (eg, Gas2), calcium and collagen binding molecules (eg, s100a6, calr3, ccar1), a negative regulator of Wnt signaling (Lrp4), and an estrogen receptor (Esr1). (Re)loading candidate genes encoded for enzymatic or catalytic processes in the cytoplasm (eg, Cap2, Agtpbp1, Ctsm, Gmds), cytoskeletal elements (Actn2), Wnt signaling (Sfrp4), and multiple functions (eg, Ctsl, Ptch1). The greater than 10-fold reduction in candidate genes resulting from a comparison of genes within the QTL to a limited number of previous gene expression studies indicates that most previously suggested mechanosensitive genes are not regulators of the magnitude of the phenotypic response observed here.

In summary, novel QTLs were identified that modulate the magnitude of changes in trabecular quantity and microarchitecture to both unloading and reambulation. The QTLs for unloading were largely distinct from those for reambulation, suggesting that these two processes are regulated by distinct sets of genes. The future definition of specific genes that cause differences in the skeletal sensitivity to weightlessness and reambulations will not only provide novel diagnostic and personalized therapeutic means of combating bone loss in space or during bed rest and paralysis but also suggest strategies to optimize bone gain during recovery based on the genetic makeup of an individual.

\section{Disclosures}

All authors state that they have no conflicts of interest.

\section{Acknowledgments}

This research was kindly funded by NASA. Expert technical help from Svetlana Lublinsky was greatly appreciated.

Authors' roles: Study design: SJ and LRD. Data acquisition: SJ, EO, WZ, and LRD. Data analysis: SJ, EO, WZ, and LRD. Drafting of manuscript: SJ and EO. Manuscript revision: SJ, EO, WZ, and LRD. All authors approved the final version of the submitted manuscript.

\section{References}

1. Vico L, Collet $P$, Guignandon A, Lafage-Proust MH, Thomas T, Rehaillia $M$, Alexandre C. Effects of long-term microgravity exposure on cancellous and cortical weight-bearing bones of cosmonauts. Lancet. 2000;355(9215):1607-11.

2. Lang T, LeBlanc A, Evans H, Lu Y, Genant H, Yu A. Cortical and trabecular bone mineral loss from the spine and hip in long-duration spaceflight. J Bone Miner Res. 2004;19(6):1006-12.

3. LeBlanc AD, Spector ER, Evans HJ, Sibonga JD. Skeletal responses to space flight and the bed rest analog: a review. J Musculoskelet Neuronal Interact. 2007;7(1):33-47.

4. Armbrecht G, Belavy DL, Backstrom M, Beller G, Alexandre C, Rizzoli R, Felsenberg D. Trabecular and cortical bone density and architecture 
in women after 60 days of bed rest using high-resolution pQCT: WISE 2005. J Bone Miner Res. 2011;26(10):2399-410.

5. Belavy DL, Beller G, Ritter Z, Felsenberg D. Bone structure and density via HR-pQCT in $60 \mathrm{~d}$ bed-rest, 2-years recovery with and without countermeasures. J Musculoskelet Neuronal Interact. 2011;11(3): 215-26.

6. Cervinka T, Rittweger J, Hyttinen J, Felsenberg D, Sievanen $H$. Anatomical sector analysis of load-bearing tibial bone structure during 90-day bed rest and 1-year recovery. Clin Physiol Funct Imaging. 2011;31(4):249-57.

7. Rittweger J, Felsenberg D. Recovery of muscle atrophy and bone loss from 90 days bed rest: results from a one-year follow-up. Bone. 2009;44(2):214-24.

8. Lang TF, LeBlanc AD, Evans HJ, Lu Y. Adaptation of the proximal femur to skeletal reloading after long-duration spaceflight. J Bone Miner Res. 2006;21(8):1224-30.

9. Judex $S$, Garman R, Squire M, Busa B, Donahue LR, Rubin C. Genetically linked site-specificity of disuse osteoporosis. J Bone Miner Res. 2004;19(4):607-13.

10. Ralston SH, Uitterlinden AG. Genetics of osteoporosis. Endocr Rev. 2010;31(5):629-62.

11. Mukherjee A, Larson EA, Carlos AS, Belknap JK, Rotwein P, Klein RF. Congenic mice provide in vivo evidence for a genetic locus that modulates intrinsic transforming growth factor beta1-mediated signaling and bone acquisition. J Bone Miner Res. 2012;27(6): 1345-56.

12. Ackert-Bicknell CL, Karasik D, Li Q, Smith RV, Hsu YH, Churchill GA, Paigen BJ, Tsaih SW. Mouse BMD quantitative trait loci show improved concordance with human genome-wide association loci when recalculated on a new, common mouse genetic map. J Bone Miner Res. 2010;25(8):1808-20.

13. Srivastava AK, Kapur S, Mohan S, Yu H, Wergedal J, Baylink DJ. Identification of novel genetic loci for bone size and mechanosensitivity in an ENU mutant exhibiting decreased bone size. J Bone Miner Res. 2005;20(6):1041-50.

14. Kapur S, Amoui M, Kesavan C, Wang X, Mohan S, Baylink DJ, Lau KH. Leptin receptor (Lepr) is a negative modulator of bone mechanosensitivity and genetic variations in Lepr may contribute to the differential osteogenic response to mechanical stimulation in the C57BL/6J and C3H/HeJ pair of mouse strains. J Biol Chem. 2010;285 (48):37607-18.

15. Robling AG, Li J, Shultz KL, Beamer WG, Turner $\mathrm{CH}$. Evidence for a skeletal mechanosensitivity gene on mouse chromosome 4. FASEB J. 2003;17(2):324-6.

16. Kesavan C, Mohan S, Srivastava AK, Kapoor S, Wergedal JE, Yu H, Baylink DJ. Identification of genetic loci that regulate bone adaptive response to mechanical loading in $\mathrm{C} 57 \mathrm{BL} / 6 \mathrm{~J}$ and $\mathrm{C} 3 \mathrm{H} / \mathrm{HeJ}$ mice intercross. Bone. 2006;39(3):634-43.

17. Robling AG, Warden SJ, Shultz KL, Beamer WG, Turner CH. Genetic effects on bone mechanotransduction in congenic mice harboring bone size and strength quantitative trait loci. J Bone Miner Res. 2007;22(7):984-91.

18. Squire $M$, Brazin A, Keng $Y$, Judex S. Baseline bone morphometry and cellular activity modulate the degree of bone loss in the appendicular skeleton during disuse. Bone. 2008;42(2):341-9.

19. Morey-Holton ER, Globus RK. Hindlimb unloading rodent model: technical aspects. J Appl Physiol. 2002;92(4):1367-77.

20. Gupta S, Vijayaraghavan S, Uzer G, Judex S. Multiple exposures to unloading decrease bone's responsivity but compound skeletal losses in C57BL/6 mice. Am J Physiol Regul Integr Comp Physiol. 2012;303(2):R159-67.

21. Bouxsein ML, Boyd SK, Christiansen BA, Guldberg RE, Jepsen KJ, Muller R. Guidelines for assessment of bone microstructure in rodents using micro-computed tomography. J Bone Miner Res. 2010;25 (7):1468-86.
22. Judex S, Luu YK, Ozcivici E, Adler B, Lublinsky S, Rubin CT. Quantification of adiposity in small rodents using micro-CT. Methods. 2010;50(1):14-9.

23. Hamilton SA, Pecaut MJ, Gridley DS, Travis ND, Bandstra ER, Willey JS, Nelson GA, Bateman TA. A murine model for bone loss from therapeutic and space-relevant sources of radiation. J Appl Physiol. 2006;101(3):789-93.

24. Kondo H, Yumoto K, Alwood JS, Mojarrab R, Wang A, Almeida EA, Searby ND, Limoli CL, Globus RK. Oxidative stress and gamma radiation-induced cancellous bone loss with musculoskeletal disuse. J Appl Physiol. 2010;108(1):152-61.

25. Laperre K, Depypere M, van Gastel N, Torrekens S, Moermans K, Bogaerts R, Maes F, Carmeliet G. Development of micro-CT protocols for in vivo follow-up of mouse bone architecture without major radiation side effects. Bone. 2011;49(4):613-22.

26. Brouwers JE, Van RB, Huiskes R. No effects of in vivo micro-CT radiation on structural parameters and bone marrow cells in proximal tibia of Wistar rats detected after eight weekly scans. J Orthop Res. 2007;25(10):1325-32.

27. Klinck RJ, Campbell GM, Boyd SK. Radiation effects on bone architecture in mice and rats resulting from in vivo micro-computed tomography scanning. Med Eng Phys. 2008;30(7):888-95.

28. Isaksson $H$, Toyras J, Hakulinen M, Aula AS, Tamminen I, Julkunen $P$, Kroger $H$, Jurvelin JS. Structural parameters of normal and osteoporotic human trabecular bone are affected differently by microCT image resolution. Osteoporos Int. 2011;22(1):167-77.

29. Lublinsky S, Ozcivici E, Judex S. An automated algorithm to detect the trabecular-cortical bone interface in micro-computed tomographic images. Calcif Tissue Int. 2007;81(4):285-93.

30. Broman KW, Wu H, Sen S, Churchill GA. R/qtl: QTL mapping in experimental crosses. Bioinformatics. 2003;19(7):889-90.

31. Sen S, Churchill GA. A statistical framework for quantitative trait mapping. Genetics. 2001;159(1):371-87.

32. Doerge RW, Churchill GA. Permutation tests for multiple loci affecting a quantitative character. Genetics. 1996;142(1):285-94.

33. Lander E, Kruglyak L. Genetic dissection of complex traits: guidelines for interpreting and reporting linkage results. Nat Genet. 1995;11 (3):241-7.

34. Durinck S, Moreau Y, Kasprzyk A, Davis S, De Moor B, Brazma A, Huber W. BioMart and Bioconductor: a powerful link between biological databases and microarray data analysis. Bioinformatics. 2005;21 (16):3439-40.

35. Squire $M$, Donahue LR, Rubin $C$, Judex $S$. Genetic variations that regulate bone morphology in the male mouse skeleton do not define its susceptibility to mechanical unloading. Bone. 2004;35(6):1353-60.

36. Kesavan C, Baylink DJ, Kapoor S, Mohan S. Novel loci regulating bone anabolic response to loading: expression QTL analysis in C57BL/ $6 \mathrm{JXC3H} / \mathrm{HeJ}$ mice cross. Bone. 2007;41(2):223-30.

37. Shimizu M, Higuchi K, Bennett B, Xia C, Tsuboyama T, Kasai S, Chiba T, Fujisawa H, Kogishi K, Kitado H, Kimoto M, Takeda N, Matsushita M, Okumura $H$, Serikawa T, Nakamura T, Johnson TE, Hosokawa M. Identification of peak bone mass QTL in a spontaneously osteoporotic mouse strain. Mamm Genome. 1999;10(2):81-7.

38. Shimizu M, Higuchi K, Kasai S, Tsuboyama T, Matsushita M, Mori M, Shimizu Y, Nakamura T, Hosokawa M. Chromosome 13 locus, Pbd2, regulates bone density in mice. J Bone Miner Res. 2001;16(11): 1972-82.

39. Beamer WG, Shultz KL, Donahue LR, Churchill GA, Sen S, Wergedal JR, Baylink DJ, Rosen CJ. Quantitative trait loci for femoral and lumbar vertebral bone mineral density in $\mathrm{C} 57 \mathrm{BL} / 6 \mathrm{~J}$ and $\mathrm{C} 3 \mathrm{H} / \mathrm{HeJ}$ inbred strains of mice. J Bone Miner Res. 2001;16(7):1195-206.

40. Klein RF, Allard J, Avnur Z, Nikolcheva T, Rotstein D, Carlos AS, Shea M, Waters RV, Belknap JK, Peltz G, Orwoll ES. Regulation of bone mass in mice by the lipoxygenase gene Alox15. Science. 2004;303(5655): 229-32. 
41. Ishimori N, Stylianou IM, Korstanje R, Marion MA, Li R, Donahue LR, Rosen CJ, Beamer WG, Paigen B, Churchill GA. Quantitative trait loci for $\mathrm{BMD}$ in an $\mathrm{SM} / \mathrm{J}$ by $\mathrm{NZB/BINJ}$ intercross population and identification of Trps1 as a probable candidate gene. J Bone Miner Res. 2008;23(9):1529-37.

42. Kleeberger SR, Schwartz DA. From quantitative trait locus to gene: a work in progress. Am J Respir Crit Care Med. 2005;171(8):804-5.

43. Capulli M, Rufo A, Teti A, Rucci N. Global transcriptome analysis in mouse calvarial osteoblasts highlights sets of genes regulated by modeled microgravity and identifies a "mechanoresponsive osteoblast gene signature". J Cell Biochem. 2009;107(2):240-52.

44. Zaman G, Saxon LK, Sunters A, Hilton H, Underhill P, Williams D, Price JS, Lanyon LE. Loading-related regulation of gene expression in bone in the contexts of estrogen deficiency, lack of estrogen receptor alpha and disuse. Bone. 2010;46(3):628-42.

45. Lau KH, Kapur S, Kesavan C, Baylink DJ. Up-regulation of the Wnt, estrogen receptor, insulin-like growth factor-I, and bone morphogenetic protein pathways in $\mathrm{C57BL} / 6 \mathrm{~J}$ osteoblasts as opposed to $\mathrm{C} 3 \mathrm{H} / \mathrm{HeJ}$ osteoblasts in part contributes to the differential anabolic response to fluid shear. J Biol Chem. 2006;281 (14):9576-88.

46. Robinson JA, Chatterjee-Kishore M, Yaworsky PJ, Cullen DM, Zhao W, Li C, Kharode Y, Sauter L, Babij P, Brown EL, Hill AA, Akhter MP, Johnson ML, Recker RR, Komm BS, Bex FJ. Wnt/beta-catenin signaling is a normal physiological response to mechanical loading in bone. J Biol Chem. 2006;281(42):31720-8. 